\title{
"I just NEED to move...": examining women's passion for physical activity and its relationship with daily affect and vitality
}

\author{
Eva Guérin ${ }^{1 *}$, Michelle S Fortier ${ }^{1}$ and Tamara Williams ${ }^{2}$
}

\author{
* Correspondence: \\ eva.eg.guerin@gmail.com \\ ${ }^{1}$ School of Human Kinetics, \\ University of Ottawa, 125 University \\ Pr, K1N 6N5, Ottawa, ON, Canada \\ Full list of author information is \\ available at the end of the article
}

\begin{abstract}
Background: Physical activity has been linked to well-being among women. One psychological perspective that can offer insights regarding this relationship is the Dualistic Model of Passion. The model posits that individuals can internalize a valued activity in an autonomous fashion, facilitating a harmonious passion, or in a controlled way, resulting in an obsessive passion. The overall purpose of this experience sampling study with physically active working mothers was to examine the influence of passion towards physical activity on daily positive and negative affect as well as more generally in terms of vitality.

Method: Sixty-three healthy and active middle-aged women participated in this study. The women attended a baseline session to complete a series of self-report questionnaires including The Passion Scale. Then, using the experience sampling method, the women responded to electronic questionnaires pertaining to their daily affect and physical activity engagement over a 14-day period. Subsequently they attended a second session during which levels of vitality were assessed. The data were analyzed using Hierarchical Linear Modeling and Analyses of Covariance.

Results: Sixty of the participants (95\%) were passionate towards physical activity. Daily positive affect was higher and negative affect lower on days when the women engaged in their passion (i.e., physical activity). On these active days, associations between overall positive and negative affect and levels of harmonious or obsessive passion were in the expected directions, albeit not significant. Levels of harmonious and obsessive passion moderated the relationship between activity engagement and positive affect such that obsessively passionate women felt significantly worse on days when they were not active. Vitality was negatively associated with obsessive passion and positively with harmonious passion.

Conclusions: The findings were consistent with the Dualistic Model of Passion and they suggest avenues of future enquiry. In considering physical activity as a strategy to optimize women's well-being, the internalization process of this activity (autonomous versus controlled) should be considered. Potential application of these results should involve facilitating more harmonious passions towards physical activity by emphasizing flexible and volitional participation that is well balanced among other activities.
\end{abstract}

Keywords: Physical activity; Passion; Daily affect; Vitality; Women; Experience sampling method; Hierarchical linear modeling

\section{严 Springer}

C 2013 Guérin et al.; licensee Springer. This is an Open Access article distributed under the terms of the Creative Commons Attribution License (http://creativecommons.org/licenses/by/2.0), which permits unrestricted use, distribution, and reproduction in any medium, provided the original work is properly cited. 


\section{Background}

\section{Women, well-being, and physical activity}

It was recently revealed that mental illness, including depression, poses a burden 1.5 times greater than that of all cancers (Ratnasingham et al. 2012). Among women, depression is the leading cause of disease-related disability (Noble 2005). Furthermore, there is evidence that mental health in general tends to be lower in women compared to men (Denton et al. 2004; Hopkins Fishel 2008). From a psycho-social perspective, there may be several compromising influences on women's mental health in today's society, for instances feelings of role overload which can arise from marked pressure on women to assume a multitude of roles (e.g., mother, professional, etc.; Lasswell 2002; Pearson 2008). Conversely, there are also protective factors capable of having a beneficial impact on women's mental health and well-being, most notably, engaging in regular physical activity (Kull 2002). Indeed physical activity $^{1}$ has been associated with greater well-being and lower symptoms of depression, especially among women (Galper et al. 2006; Penedo and Dahn 2005).

Women's regular engagement in physical activity has also been linked with several specific indices of well-being including positive affect (Elavsky and McAuley 2005; Gauvin et al. 2000; Kull 2002). Affect is defined as the subjective characteristic of an individual's feeling state and it is often described along two dimensions: valence (positive, negative) and activation (high, low; Russell, 1980; 2003). Researchers have demonstrated the beneficial influence of physical activity on women's affective states immediately after the activity (Cramp and Bray 2010; Guérin and Fortier 2012) and in terms of their general affectivity (i.e., Kelsey et al. 2006). Vitality is another subjective indicator of well-being that has received increased attention in the context of exercise and that is more eudaimonic (i.e., focused on self-realization and growth) and enduring in nature.. Vitality refers to meaningful feelings of positive energy and enthusiasm (Ryan and Frederick 1997). Vitality is an individual's dynamic and subjective experience of aliveness, and although it is informed by one's physical state, it is of a more psychological quality (Nix et al. 1999). Not surprisingly, experiencing greater levels of vitality is another beneficial outcome of regular physical activity engagement, particularly among women (Brown et al. 2000; Wendel-Vos et al. 2004).

However, does engaging in physical activity always or necessarily lead to greater wellbeing, be it vitality, positive affect, or other indices? Existing literature has led experts to raise such enquiries (Biddle and Ekkekakis 2005). (Vancour 2009) remarked that many professional women, for instance, feel a pressure to create a balance between heavy work demands and multiple roles while also incorporating practices of a healthy lifestyle (i.e., exercise). This could result in a controlled orientation, or sense of obligation toward engaging in physical activity, which might not be optimal for one's greater well-being. Indeed, feelings of guilt and pressure towards physical activity have been linked with excessive or rigid engagement in this behaviour, and this can have dire consequences in terms of well-being (Hamer et al. 2002; Hausenblas and Downs 2002). Thus, there is reason to believe that we need a more sophisticated understanding of the circumstances under which physical activity leads to greater well-being. Psychological theory can help direct exploration in this regard; in fact, theory has been highly recommended to determine how physical activity contributes to individuals' well-being (Berger and Motl 2000; Reed and Buck 2009). One theoretical perspective that offers strong, well-supported tenets that link activities, such as physical activity, with important indicators of well-being is the Dualistic Model of Passion (Vallerand et al. 2003). 


\section{Dualistic Model of Passion (DMP) Description}

Vallerand et al. (2003) proposed a novel approach to the study of passion wherein passion is characterized by an investment of time and energy in an activity that one likes, values, and assimilates into one's identity, and which has the potential to lead to positive outcomes. Differences between the DMP and motivational frameworks such as Self-Determination Theory are described elsewhere (e.g., Vallerand et al., 2003; Vallerand, 2012). Researchers have shown that sport/physical activity is a top rated passion category and that many active people are passionate about this activity in their life (Vallerand et al. 2003; Rousseau and Vallerand 2008). Therefore, this context is ideally suited to study passion, adding to the fact that passion for physical activity or sport can inherently give rise to several worthy outcomes, such as fitness and health (Vallerand 2010). However, few passion studies have been conducted in the physical activity domain specifically (Parastatidou et al. 2012) and none have uniquely targeted women.

In addition, because passionate people are engaging in an activity that is highly valued, there is a close link between passion and affective consequences (Vallerand 2010; Vallerand 2012). Given that a great deal of time is spent partaking in the passionate activity (Vallerand et al., 2003, study 1; 2008 study 1) and considering aforementioned affective benefits of physical activity among women, it would be interesting to consolidate these streams of research. Thus a first purpose of this study was to examine, among active women who are passionate for physical activity, whether they experience improved affect on days when they engage in their passion (i.e.., physical activity) versus days when they do not.

The unique and defining element of the DPM is its representation of passion's inherent dualism (Vallerand 2010). In essence, the consequences of engaging in a passionate activity (i.e., affect) may depend on the way this activity is internalized and incorporated into one's identity (Vallerand et al. 2003, 2007). According to the stated model, distinct internalization processes can lead to the development of two types of passion: harmonious passion (HP) and obsessive passion (OP). When physical activity is engaged in with a sense of volition and choice, it becomes internalized in an autonomous fashion, thus leading to a harmonious form of passion (Vallerand et al. 2003). With a HP, the activity is well-balanced in one's identity and it is 'in harmony' with other aspects of one's life. Conversely, an OP for physical activity arises from a controlled internalization whereby one likes the activity but feels a compelling, overwhelming urge to engage in it, as described earlier. Thus, contingencies become attached to the activity as a result of intraand inter-individual pressures to pursue it. The differential psychological consequences of HP and OP have been studied across several life domains (Vallerand 2008).

\section{Type of passion and affect}

According to the DMP, experiencing positive affect to its fullest can be thwarted by the rigid and controlling nature of an OP (Vallerand 2010). Studies have supported that OP for an activity is associated with lower levels of positive affect as well as more reports of negative affect, particularly in the form of shame and anxiety (Rousseau and Vallerand, 2008; Vallerand et al. 2003; study 1; Vallerand 2008). Conversely, the freedom and flexibility of a HP allows individuals to fully engage in an activity thus maximizing positive affect experiences that ensue, and over time, allowing for greater well- 
being (Vallerand 2012). Not surprisingly, HP has been associated with higher positive affect following the activity (Mageau et al. 2005), from day to day (Mageau and Vallerand 2007), and in general across time (Vallerand et al. 2003; study 2).

Although these associations have seldom been tested with respect to physical activity, in a sample of active older adults (Rousseau and Vallerand 2008) found that HP predicted greater subjective well-bring over time by increasing positive affect during physical activity. Parastatidou et al. (2012) showed that HP had a stronger positive association with exercise enjoyment than OP, although they did not assess positive affect directly nor any more generalized effects over time. To our knowledge, no study has been conducted with active women to specifically look at the influence of passion (i.e., HP and OP) on their daily positive and negative affect when they do engage in physical activity in their busy day-to-day lives. This was the second objective of the present study. Moreover, this was accomplished using repeated, overall daily measures over a 14-day period, whereas the above studies employed cross-sectional designs or drew from a few select time points.

Passion types can be further distinguished relative to how an individual is impacted by being unable to engage in the activity (Vallerand et al. 2003). Because OP is characterized by overvaluation and an uncontrollable desire to partake in the activity, it follows that not engaging in the activity would lead to declines in positive affect and increments in negative affect. Conversely, the volitional and balanced qualities of HP would protect against such deleterious effects. Research supports these associations for the high activation components of affect (Ratelle et al. 2004; Vallerand 2010). For instance, in a college sample with a diversity of passions, (Mageau and Vallerand 2007) found that OP moderated the effect of activity engagement on positive high activation affect at the end of the day. It is reasonable to assume that active, working mothers would exhibit a unique and at times uncontrollable balancing act with respect to a passion for physical activity among several other responsibilities. Therefore, it was deemed theoretically and practically pertinent to examine, as another purpose, whether the differential effect of engaging in one's passion (physical activity) on a given day, versus not, on overall daily affect is moderated by passion types in this population. This would be the first study to explore this proposition across four dimensions of affect (high, low, positive negative).

\section{Type of passion and vitality}

While optimal affective states are worthy outcomes in themselves, passion researchers have also assessed more global and longstanding indicators of well-being such as satisfaction with life and vitality (Rousseau and Vallerand, 2008; Philippe et al. 2009; Vallerand and Houlfort, 2003). Consistent with the dual conceptualization, research has shown that HP holds a positive, prospective association with vitality. Philippe et al. (2009) assessed vitality as an indicator of eudaimonic well-being and saw that a group of harmoniously passionate participants, compared to an obsessively passionate group, experienced an increase in vitality one year later. Vitality levels were also higher among women. Little research in the passion tradition has used measures of both cumulative short-term/daily indicators of well-being as well as those that reflect more enduring, eudaimonic facets of well-being in the context of the same study (Rousseau and Vallerand, 2008). Moreover, given the evidence that physical activity may be particularly 
beneficial for women's vitality, understanding the influence of passion would provide a psychological link that extends above and beyond simply engaging in the activity. This was examined in the final purpose of this study.

\section{Experience sampling and passion}

Lastly, some passion researchers have taken to conducting diary studies (also known as the experience sampling method) to investigate daily fluctuations in activity engagement and affect (Mageau and Vallerand 2007; Verner-Filion et al. 2012). The experience sampling method refers to the real-time acquisition of participants' self-reported thoughts feelings and/or behaviours in their natural everyday environments and it has been praised for providing externally valid results (Hektner et al. 2007; Scollon et al. 2003). This approach is also ideally suited for examining day-to-day physical activity patterns specifically (e.g., Hyde et al. 2011). Therefore, data for the present study were acquired using the experience sampling method in the context of physically active working mothers' daily lives.

\section{Purposes}

The first aim of this experience sampling study with active, multiple-role women was to investigate the influence of engaging in one's passion (i.e., physical activity) on daily positive and negative affect (high and low activation). It was expected that women would report greater positive-and lower negative affect on days when they engaged in their passionate activity versus days when they do not (Mageau and Vallerand 2007; Wichers et al. 2012). The second purpose was to look at the influence of passion types on daily positive and negative affect on days when women engaged in physical activity. It was hypothesized that a) levels of HP would be positively associated with positive affect and negatively related to negative affect, while b) reverse or non-significant associations would arise for OP levels (Rousseau and Vallerand, 2008; Vallerand 2012). The third objective was to examine whether levels of HP and OP would moderate the effect of activity engagement on daily affect. It was presumed that higher OP would result in lower positive-and greater-negative affect on non-physical activity days compared to activity days (Mageau and Vallerand 2007). The discrepancy in affect across days would diminish with higher HP (Vallerand 2010). These relationships were dissected by comparing participants classified as more harmoniously passionate and those more obsessively passionate (i.e., groups).

The fourth purpose of this study was to examine, controlling for physical activity levels and using two complementary types of analyses, the relationship between HP as well as OP and levels of vitality measured two weeks later. Via group differences, we expected women in an harmoniously passionate group, versus an obsessive group, to show greater levels of vitality. With prospective regression, we hypothesized a positive relationship between HP and vitality, accompanied by a weak or negative association for OP (Philippe et al. 2009).

\section{Method}

\section{Context}

This study was embedded within a larger research program on active women and their various social roles (Guérin et al. Unpublished). As such, the following inclusion criteria 
were employed to screen all participants for eligibility: a) female aged between 25 and 55 , b) mother with one child aged 18 or younger still living in the home, c) physically active (i.e., meeting the Canadian PA Guidelines of a minimum of 150 minutes of moderate to vigorous PA per week (Tremblay et al. 2010), d) working full-time outside of the home (minimum of 30 hours/week), e) currently free from any underlying medical or mental health condition that would influence physical activity levels or impair mood.

\section{Participants}

The participants were recruited by several means, including snowball sampling and word of mouth promotion of this study. Moreover, a recruitment text appeared in several professional and athletic e-newsletters and information posters were positioned in athletic centers and sport/ children's stores in a large city. Interested participants emailed or telephoned the research team in order to receive details about the study. The researchers reviewed the inclusion criteria with each participant to ensure that she was eligible to partake. Failure to satisfy one or more of the criteria, being unable to commit to the study's time requirements, or being unreachable for scheduling resulted in thirty-one women being eliminated. Another three women were excluded after the study as a result of errors during the recording or transferring of data.

The final sample consisted of 63 very active, healthy women [i.e., mean Godin Leisure Time Exercise Questionnaire (LTEQ) score of 51.73, $S D=18.55$; Godin and Shephard, 1985 ] They had a mean age of 42.60 years $(S D=5.59)$. Calculations using self-reported height and weight showed that they had a healthy BMI of 22.70 on average $(S D=2.68)$. These mostly Caucasian (89\%) women were well-educated (83\% with bachelor's degree or higher) and reported a variety of professions such as nurse, professor, assistant director, etc. More than half were legally married at the time of the study (70\%), 11 participants were separated or divorced and seven were living with a partner. The women had an average of two children $(S D=.92)$ with a mean age of 10.42 years $(S D=5.02)$. Fourty-five percent of the participants reported spending five or more hours per weekday in unpaid childcare-related activities.

\section{Procedures \& measures}

This study was approved by the University of Ottawa Research Ethics Board. The protocol is described in the sections that follow, interposed with descriptions of the measures that were employed at two in-person sessions (two weeks apart) as well as those administered via the Experience Sampling Method (ESM; Csikszentmihalyi and Larson 1987).

\section{Baseline session}

At the first of two individual sessions, participants provided their written consent after being informed of the general purpose and requirements of this study. A brief instructional session was delivered to explain an electronic questionnaire application that was developed for this study and that was loaded onto participants' personal electronic devices. For any woman that borrowed a device supplied by the research team, more thorough directions were offered until she felt comfortable with the tool. The timing requirements of the questionnaires, that is, immediately after physical activity and at 
night before bed, were duly explained. Participants also completed the following set of baseline measures.

\section{Demographics}

A basic demographic questionnaire was administered in order to describe the women in this sample. There were questions pertaining to ethnicity, education level, income, marital status, number-and age of children and ages, and general health status. The women were also asked about the number of hours they spend per day in different roles, including childcare-related activities.

\section{Passion}

The Passion Scale was used to evaluate passion towards physical activity (Vallerand et al. 2003; Parastatidou et al. 2012). Participants were asked to think about this activity when responding to the two components of the scale. All descriptive items were scored on a 7-point Likert scale from (1) do not agree at all, to (7) very strongly agree. The four items that make up the first component of the scale assess the extent to which one is passionate about the activity (e.g., devote time and energy to it). Being 'passionate' is defined as having a mean score above the mid-point (i.e., four) across these items. The second component evaluates the two types of passion (HP, OP) and is comprised of 12 descriptive items, six per passion type. Examples of items include "This activity reflects the qualities I like about myself" (HP) and "I am emotionally dependent on this activity" (OP). Studies have shown high reliability and theoretical validity for the scale and findings have also supported a two-factor structure in the physical activity domain (Mageau and Vallerand 2007; Parastatidou et al. 2012; Rousseau and Vallerand 2008). Scores for HP and OP are computed by taking the mean of the items in each subscale. The Cronbach's alpha values for HP and OP were .77 and .88 respectively, which were similar to those of others such as (Donahue et al. 2009) in the sport context.

\section{Experience sampling}

Participants were directed to begin the experience sampling component of the study the day after the baseline session and for 14 continuous days thereafter. They were encouraged to engage in their normal, daily activities, which could include any brief lapses or surges in physical activity. The present study made use of interval-contingent sampling (i.e., end of the day) as well as event-contingent sampling (i.e., physical activity session; for details, see Hektner, et al. 2007). Via electronic questionnaires, participants provided a description of their activity after each moderate-to-vigorous session (event) and they rated their overall daily affect every night before going to sleep (interval). An assessment at the end of the day offers a good evaluative judgment of average mood over the course of one day and it has been employed in previous passion studies (Giacobbi et al. 2005; Mageau and Vallerand 2007).

The questionnaires were administered using an Apple@ application that was developed for iPod Touches and iPhones® for the purposes of the larger project. After selecting the appropriate questionnaire from a menu page, participants scrolled down the screen and responded to each item individually. All responses were time-and datestamped and were submitted through a safe and password protected server. Additional 
features of the application included an 'End-of-Day' questionnaire reminder, where participants could opt to receive a subtle alert on the device at a designated time. In addition, every questionnaire timed out automatically after 30 minutes to prevent erroneous or time-lagged recordings.

\section{Activity description (post-physical activity)}

After each physical activity session over the 2-week period, the women recorded three pieces of information for descriptive purposes: a) the type of activity they performed (e.g., running), b) the amount of time engaged, and c) a subjective rating of the intensity of the activity. The latter was assessed using the Rating of Perceived Exertion (RPE; Borg 1982), a reliable self-report measure of intensity that is commonly employed in exercise-based studies examining affect (Russell and Newton 2008). Respondents selected their intensity value (RPE) from a series of descriptors at every odd integer on a 6 -20 scale (i.e., $7=$ very, very light; $13=$ somewhat hard; $19=$ very, very hard).

\section{Daily affect}

Participants' overall daily positive and negative affect were assessed at the end of each day using the Positive and Negative Affect Schedule (PANAS; Watson et al. 1988). This measure is commonly employed by physical activity researchers as well as by others assessing the links between passion and affective states (e.g., Reed and Buck 2009; Rousseau and Vallerand, 2008). Participants were instructed to indicate the extent to which they had felt this way today for each of 20 adjectives (10 positive), for example "interested" and "upset", using a 5-point Likert-type scale ranging from (1) not at all to (5) extremely.

(Ekkekakis and Petruzzello 2001) contend that the PANAS is a measure of high activation affect only (i.e., excited/energetic state). Hence, other researchers have supplemented the PANAS with 11 items assessing low activation affect (i.e., calm/relaxed state) and these were also integrated into the present study (Abercrombie et al. 2005). ${ }^{2}$ This approach is warranted in order to address the complexity of affect, particularly as exercise-based arousal levels may wane over the course of a day (Barrett and Russell 1998; Kwan and Bryan 2010). Values for positive and negative affect were summed separately by activation to provide daily affect score with possible ranges of 10-50 and 5-25 for high and low activation respectively. In the present study, high internal consistency values were obtained across time and participants for all four affect types $(\alpha$ range $=.78-.94)$.

\section{Activity engagement (daily)}

The participants were also asked to provide a dichotomous yes/no rating of physical activity engagement at the end of each day. This served two goals. First, it helped to address the possibility that participants may forget or be unable to log each post-activity description over the 14 days. Second, it served as partial validation of the post-physical activity description.

\section{Endpoint session}

Participants attended a second session approximately two weeks after the first in order to return the device (if applicable) and ensure that all data were properly transferred 
and deleted from the device. They also responded to one final set of questionnaires. The women were debriefed and presented with a gift card for their involvement in the study.

\section{Physical activity levels}

Given the focus of the present study, a global retrospective account of participants' physical activity levels in the last two weeks was obtained for descriptive purposes and to control for this variable in regression analyses. Activity levels were quantified using the Godin LTEQ (Godin and Shephard 1985). The LTEQ is a valid and reliable measure of physical activity across different populations, including active individuals (e.g., Duncan et al. 2010; Jacobs et al. 1993). Participants were asked to consider the last two weeks in evaluating the number of times per week they engaged in light, moderate, and strenuous intensity physical activity (examples provided). To create a weekly activity score, the frequency values are multiplied by their respective MET intensity value, namely three, five, and nine. Scores above 14 are considered moderately active and scores above 24 are active (Godin 2011).

\section{Vitality}

The vitality subscale of the Short-Form (SF-36) Health Survey of the Medical Outcomes Study was used to assess vitality (Ware and Sherbourne 1992). Respondents indicated how much of the time over the past month they had been feeling in regards to four items assessing feelings of energy and aliveness (e.g., "Have you felt calm and peaceful?"). Responses were scored on a scale from (0\%) none of the time to (100\%) all of the time. The subscale has been described as a valid and reliable indicator of eudaimonic well-being (Vuillemin et al. 2005; Ware 2000). In this study, the measure demonstrated adequate internal consistency $(\alpha=.83)$

\section{Analyses}

\section{Preliminary}

Baseline and endpoint data were entered directly into SPSS Statistics 20 and summary statistics were computed. Passion groups were created by identifying participants' highest standardized scores on the two passion subscales (Philippe et al. 2009; Mageau et al. 2009). This practice is informative given that when individuals are passionate for an activity, they tend to strongly endorse items from both subscales, resulting in blurred distinction between "purely" passionate people of either type and those that are mixed. Therefore, by drawing on standardized scores, two similarly sized groups of relatively more harmonious and relatively more obsessive participants are created.

As for the experience sampling data, individual datasets were downloaded from the server as Excel files before being exported into SPSS. Then, the sums and means of the post-physical activity and end-of-day affect variables were computed by aggregating scores across the 14 days. If participants had reported a post-activity description on a given day but had not logged the end-of-day measures, a "yes" was imputed as the value for having engaged in activity that day (PANAS items were not imputed). For all data (baseline, daily, endpoint), the distributions of the variables were examined in terms of outlying values, skewness, and kurtosis. In short, all standard assumptions of 
univariate and multivariate regression analyses were examined, for instance, Mahalanobis distances, multicollinearity and so forth (Tabachnick and Fidell 2007).

\section{Daily affect}

The hierarchical structure of the data acquired in this study, namely the daily assessments of positive and negative affect (level 1) nested within stable individual-level passion variables (level 2), warranted the use of hierarchical linear modeling (HLM; Raudenbush and Bryk 2002; Nezlek 2008). The data were restructured to be treated using HLM 6.0 statistical software (Raudenbush et al. 2004). Some advantages of HLM versus analyses of aggregate scores include its ability to reliably estimate relationships within-participants as well as its capacity to manage missing data (Giacobbi et al. 2005; Nezlek 2008).

With HLM analyses, the intercept of an equation indicates the between-person variability of means on the outcome variable when any level 1 predictor in the equation is equal to 0 . The type of centering that is applied to the level 1 predictor (or no centering) will influence how the intercept is understood. The same principles govern the interpretation of the grand-mean of participants when level 2 predictors are included. In the present study, the level 1 predictor consisted of the dichotomous physical activity engagement variable, with "yes" dummy coded as " 0 " and "no" coded as " 1 ". This variable was left uncentered, and thus the intercept corresponded to participants' means on the outcome variable for the category coded as "0", in this instance, having engaged in physical activity that day. The level 2 predictors in this study were the two passion types (HP, OP) and these were grand- or sample-mean centered. In this case, the intercept represents the mean on the outcome variable across all participants. To illustrate the equations that were tested, readers are invited to consult Table 1 and (Mageau and Vallerand 2007) for a more detailed description. In initial analyses, intercepts and slopes were set as randomly varying. They were revised to be fixed if coefficients were estimated with low reliability or if errors terms were not significantly variable between participants. Separate equations were tested for the four types of affect (i.e., positive, negative, high-low-activation).

The full-maximum likelihood estimation was used and the hypotheses for purposes one to three were evaluated via t-tests of model coefficients (McCoach and Black 2008). Robust standard errors were evaluated in order to circumvent issues arising with violations of homogeneity of variance. A log likelihood test of fit improvement in HLM (using $X^{2}$ ) was used to test the superiority of models with the inclusion of additional variables (Hox 2010; Raudenbush et al. 2004). To help with interpretation, pseudo- $R^{2}$ was calculated as a measure of effect size by subtracting the unexplained variance from a restricted model (with predictors) from the unexplained variance of an unrestricted model (no predictors) and dividing by the unexplained variance in the unrestricted model (Kreft and De Leeuw 1998; Raudenbush and Bryk 2002).

\section{Vitality}

To examine the influence of passion on endpoint vitality, two complementary types of analyses were conducted. First, harmoniously passionate and obsessively passionate women were compared with respect to vitality using an ANCOVA controlling for LTEQ scores (i.e., endpoint physical activity). Second, all passionate participants were 
Table 1 Models predicting daily high activation (HA) positive affect

\begin{tabular}{|c|c|c|c|c|c|}
\hline Model & Estimate & SE & Model & Estimate & SE \\
\hline \multicolumn{6}{|c|}{ 1. PA (vs. no-PA) with high activation affect } \\
\hline \multicolumn{6}{|l|}{ Fixed effects } \\
\hline Intercept, $\beta_{00}$ & $29.64^{* * *}$ & 0.97 & & & \\
\hline $\mathrm{PA}, \beta_{10}$ & $-3.38^{* * *}$ & 0.69 & & & \\
\hline \multicolumn{6}{|l|}{ Random effects ${ }^{a}$} \\
\hline Intercept, $\sigma_{u o}^{2}$ & $52.77^{* * *}$ & 7.26 & & & \\
\hline $\mathrm{PA}, \sigma_{u 1}^{2}$ & $11.92^{* * *}$ & 3.45 & & & \\
\hline Residual variance, $e$ & 27.76 & 5.27 & & & \\
\hline
\end{tabular}

2. A) PA (vs. no-PA) and passion with high 2. B) PA (vs. no-PA) and passion with high activation activation affect

Fixed effects affect; slope only

\begin{tabular}{|c|c|c|c|c|c|}
\hline Intercept, $\beta_{00}$ & $29.64^{* * *}$ & 0.96 & Intercept, $\beta_{00}$ & $29.64^{* * *}$ & 0.96 \\
\hline Harmonious passion, $\beta_{01}$ & 0.16 & 1.02 & $\mathrm{PA}, \beta_{10}$ & $-3.34^{* * *}$ & 0.64 \\
\hline Obsessive passion ${ }^{\mathrm{b}}, \beta_{02}$ & -2.30 & 4.58 & Harmonious passion, $\beta_{11}$ & $1.67^{* *}$ & 0.62 \\
\hline $\mathrm{PA}, \beta_{10}$ & $-3.34^{* * *}$ & 0.65 & Obsessive passion ${ }^{\mathrm{b}}, \beta_{12}$ & $-5.89^{*}$ & 2.64 \\
\hline Harmonious passion, $\beta_{11}$ & $1.62^{*}$ & 0.62 & Random effects $^{a}$ & & \\
\hline Obsessive passion ${ }^{\mathrm{b}}, \beta_{12}$ & $-5.09^{\dagger}$ & 3.19 & Intercept, $\sigma_{u o}^{2}$ & $52.60^{* * *}$ & 7.25 \\
\hline Random effects ${ }^{a}$ & & & $\mathrm{PA}, \sigma_{u 1}^{2}$ & $10.03^{* * *}$ & 3.17 \\
\hline Intercept, $\sigma_{u o}^{2}$ & $52.37^{* * *}$ & 7.24 & Residual variance, $e$ & 27.72 & 5.26 \\
\hline $\mathrm{PA}, \sigma_{u 1}^{2}$ & $10.01^{* * *}$ & 3.16 & & & \\
\hline Residual variance, $e$ & 27.72 & 5.26 & & & \\
\hline
\end{tabular}

Note. Unstandardized Estimates; $S E=$ Standard Error; $P A=$ Physical Activity. Level 1: Daily positive affect $\left(Y_{p i}\right)=\beta_{0 i}+\beta_{1 i}(P A$ engagement $\left.\mathrm{p}_{\mathrm{i}}\right)+\mathrm{r}_{\mathrm{pi}}$. Level 2: $\beta_{0 \mathrm{i}}=\gamma_{00}+\gamma_{01}$ (Harmonious Passion) $+\gamma_{02}$ (Obsessive Passion) $+u_{0 i} ; \beta_{1 i}=\gamma_{10}+\gamma_{11}$ (Harmonious Passion) $+\gamma_{12}$ (Obsessive Passion) $+u_{1 i}$.

${ }^{a}$ Variance component estimates and standard deviations are provided for Random Effects.

${ }^{\mathrm{b}}$ Log transformed Obsessive passion variable.

${ }^{\dagger} \mathrm{p}=.10 .{ }^{*} \mathrm{p}<.05 .{ }^{* *} \mathrm{p}<.01 .{ }^{* * *} \mathrm{p}<.001$.

included together in hierarchical regression analyses to examine the relative influence of HP and OP levels on vitality. Scores on the LTEQ as well as any other relevant demographic variables such as age were controlled for.

\section{Results}

Data cleaning and preparation

Out of the 63 women in the final sample, three scored below the midpoint on passion criteria items of the Passion Scale (i.e., non-passionate) and were excluded from the main analyses, as per (Donahue et al. 2009). All analyses were conducted on the 60 participants who were passionate for physical activity. ${ }^{3}$ The distributions of all variables (i.e., baseline, daily, endpoint) were closely examined to verify assumptions. The obsessive passion variable demonstrated a skewed distribution therefore a log transformation of this variable was employed in all statistical tests (Hair et al. 1998).

Moreover, the negative affect variables (high, low activation) showed very skewed distributions that could not be corrected with standard data cleaning actions such as transformations (Hair et al. 1998; Tabachnick and Fidell 2007). Specifically, most participants scored very low on daily negative affect. To address the issue, each negative affect variable was dichotomized as "high" and "low" based on the values that partitioned the observations into pairs of relatively evenly sized categories. Specifically 
a) for high activation negative affect, scores equal to 12 or greater were considered "high" and coded as "1" (< 12 as "0") and b) for low activation negative affect, scores equal to 11 or greater were considered "high" and coded as "1" (< 11 as "0"). Given binary variables, HGLM was used to test negative affect models using a log-link function with a Bernoulli distribution (Raudenbush et al. 2004). Specifically, unit-specific models (correcting for overdispersion) with robust standard errors were examined to determine the odds of scoring high on negative affect.

There were no other deviations from normality on the main variables. The division of participants into passion groups resulted in a harmoniously passionate group consisting of 33 women who displayed higher HP and lower OP levels than the obsessively passionate group $(\mathrm{n}=27)$. The groups were significantly different in terms of HP, $t(58)=-5.26, p<.001$, and OP levels, $t(58)=4.90, p<.001$.

\section{Physical activity summary}

Table 2 presents descriptive statistics and the number of data points for baseline and endpoint variables as well as for the experience sampling data post-physical activity and at the end of each day. The average RPE rating for the intensity of physical activity sessions across all participants was $14.61(S D=2.17)$, which can be labeled as "hard" and of moderate-to-vigorous intensity (Borg, 1982). ${ }^{4}$ The women described a wide variety of physical activities, including, but not limited to: running, swimming, spinning, hiking, and skiing. In terms of the overall frequency of physical activity engagement as reported in the end-of-day questionnaires, participants answered 'yes' to having engaged in physical activity on 9.93 days or $71 \%$ of days (range: 4-14). They reported "no" on an average of 2.92 days out of the 14 .

\section{Purpose 1: physical activity and daily affect Positive affect}

In the unconditional model for daily high activation positive affect, the average across days was moderate at $28.85(S E=.92)$. In the first conditional model (Table 1), there was a significant association between engaging in the passionate activity on a given day and levels of positive affect, $t(59)=-4.92, p<.001$, and this relationship varied between participants. Because engaging in physical activity was coded as 0 , the negative coefficient indicates that high activation positive affect was significantly higher (by 3.38 points) on days when the women were active (versus not). This model explained 12\% of within-person variance.

For low activation positive affect, an unconditional model revealed that the average across all days was relatively high $(M=16.11, S E=.38)$. This model revealed a significant association between engaging in physical activity on a given day (versus not) and levels of daily low-activation positive affect, $t(59)=-6.35, p<.001$, and this varied between participants (Model 3 in Table 3). More specifically, low-activation positive affect was also higher on days when the women engaged in physical activity. Notably, there was a 2.10 point increase from days when the women were not active to days they were. This model explained a similar $12 \%$ of within-person variance in low activation positive affect. 
Table 2 Descriptive statistics for baseline, daily experience sampling and endpoint variables

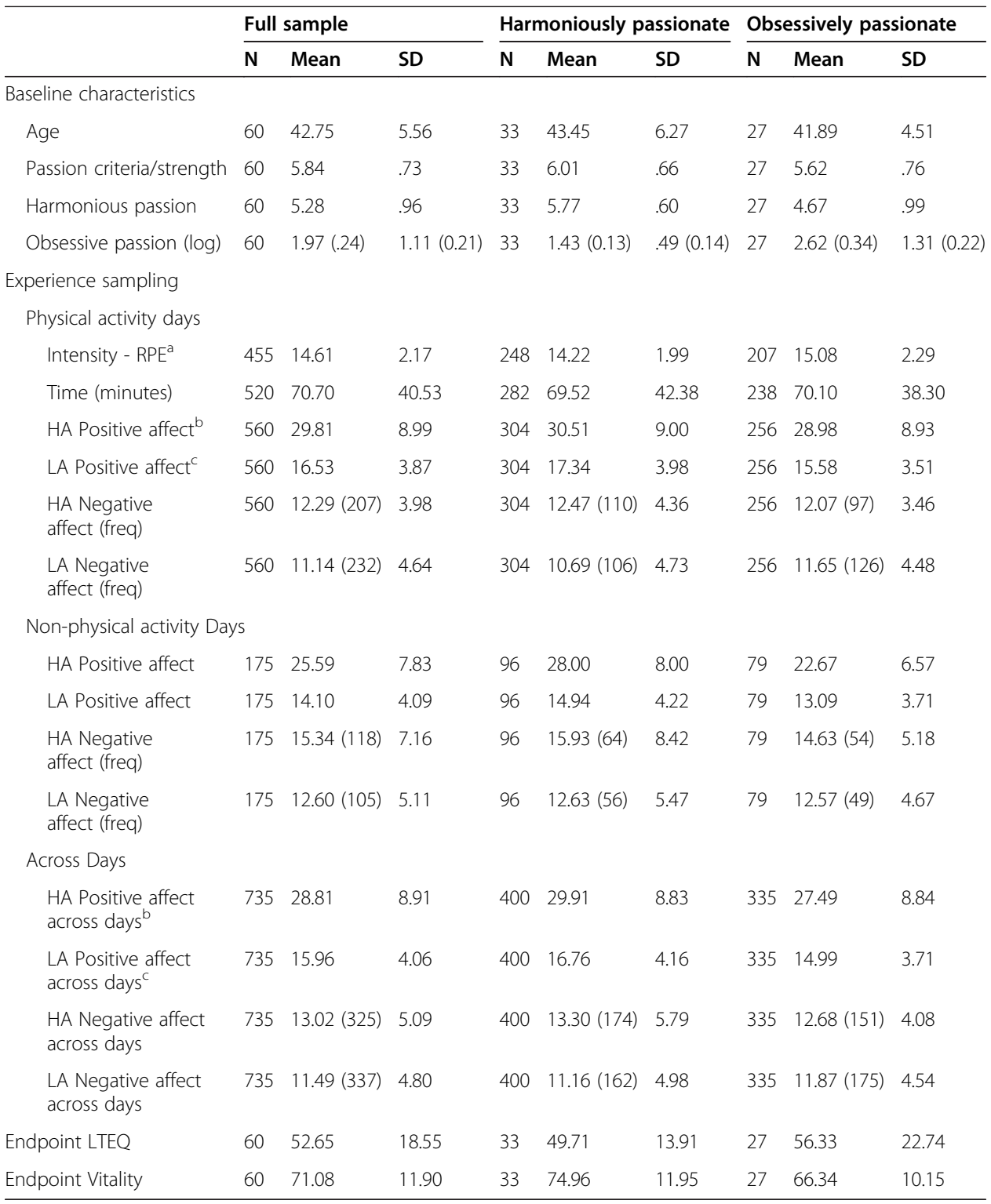

Note. $\mathrm{SD}=$ Standard Deviation; RPE = Rating of Perceived Exertion; HA = High Activation; LA = Low Activation; freq = Frequency of values in the "high" category (i.e., number of observations labeled as "high", for instance for HA negative affect, 207 out of 560 responses were coded as high or "1"); LTEQ = Godin Leisure Time Exercise Questionnaire. ${ }^{\mathrm{a} B o t h}$ RPE and Time showed skewed distributions even after accounting for the influence of outliers. The variables were left untransformed since no subsequent analyses for these variables are presented in this paper.

${ }^{b}$ ICC (Intra-class correlation) of experience sampling HA positive affect: .66(PA days), .61 (across all days).

ICC (Intra-class correlation) of experience sampling LA positive affect: .51 (PA days), .48 (across all days).

\section{Negative affect}

Engaging in physical activity on a given day was significantly associated with high activation negative affect such that "high" values were more likely on days when participants were not active, $t(713)=5.43, p<.001$. An unconditional Bernoulli model revealed that the probability of an elevated score on high activation negative affect (i.e., above 12 ) across all days was $41.8 \%$, but this dropped to $34.71 \%$ on days when the women did engage in physical activity (see Table 4 for odds ratios). 
Table 3 Models predicting daily 'low activation' positive affect

\begin{tabular}{|c|c|c|}
\hline Model & Estimate & SE \\
\hline \multicolumn{3}{|c|}{ 3. PA (vs. no-PA) with low activation affect } \\
\hline \multicolumn{3}{|l|}{ Fixed effects } \\
\hline Intercept, $\beta_{00}$ & $16.61^{* * *}$ & 0.39 \\
\hline $\mathrm{PA}, \beta_{10}$ & $-2.10^{* * *}$ & 0.33 \\
\hline \multicolumn{3}{|l|}{ Random effects ${ }^{a}$} \\
\hline Intercept, $\sigma_{u o}^{2}$ & $8.03^{* * *}$ & 2.83 \\
\hline $\mathrm{PA}, \sigma_{u 1}^{2}$ & $2.09^{*}$ & 1.45 \\
\hline Residual variance, $e$ & 7.58 & 2.75 \\
\hline \multicolumn{3}{|c|}{ 4. PA (vs. no-PA) with low activation affect } \\
\hline \multicolumn{3}{|l|}{ Fixed effects } \\
\hline Intercept, $\beta_{00}$ & $16.61^{* * *}$ & 0.38 \\
\hline Harmonious passion, $\beta_{01}$ & 0.58 & 0.42 \\
\hline Obsessive passion ${ }^{\mathrm{b}}, \beta_{02}$ & -2.39 & 1.94 \\
\hline $\mathrm{PA}, \beta_{10}$ & $-2.09^{* * *}$ & 0.33 \\
\hline Harmonious passion, $\beta_{11}$ & 0.34 & 0.38 \\
\hline Obsessive passion ${ }^{\mathrm{b}}, \beta_{12}$ & -1.04 & 1.86 \\
\hline \multicolumn{3}{|l|}{ Random effects $^{\mathrm{a}}$} \\
\hline Intercept, $\sigma_{u o}^{2}$ & $7.54^{* * *}$ & 7.54 \\
\hline$P A, \sigma_{u 1}^{2}$ & $1.88^{*}$ & 1.37 \\
\hline Residual variance, $e$ & 7.89 & 2.75 \\
\hline
\end{tabular}

Note. Unstandardized Estimates; SE = Standard Error; PA = Physical Activity. See Equations Table 1.

avariance component estimates and standard deviations are provided for Random Effects.

${ }^{\mathrm{b}}$ Log transformed Obsessive passion variable.

${ }^{\dagger} \mathrm{p}=.10 .{ }^{*} \mathrm{p}<.05 .{ }^{* *} \mathrm{p}<.01 .{ }^{* * *} \mathrm{p}<.001$.

Results from a similar conditional model for low activation showed that reporting greater scores on negative affect was significantly more likely on days when participants did not engage in physical activity, $t(59)=2.97, p<.01$, an association that varied between participants, $X^{2}(50)=80.55, p<.01$. The findings revealed that across all days, there was a $46.1 \%$ probability of showing elevated levels of low activation negative affect. On days when the women were active, this probability dropped by $5 \%$.

\section{Purposes 2 and 3: passion types, physical activity, and daily affect}

\section{Positive affect}

The first conditional model tested was an analysis of slopes and means as outcomes in order to examine the direct and moderating influence of passion variables (HP and OP) on daily high activation positive affect. This model provided a better fit than the more basic model (Model 1 in Table 1 ) consisting of physical activity engagement only, $x^{2}$ $(4)=9.26, p=.05$. Although the coefficients were in the expected directions, neither HP levels, $t(57)=0.15, p=.88$, nor OP levels, $t(57)=-0.49, p=.63$, were significantly associated with high activation positive affect on days when participants were active (i.e., the intercept). ${ }^{5}$ However, coefficient values depicted in Model 2-A in Table 1 revealed a trend (i.e., higher estimates, lower $p$ values) that favoured the influence of the passion 
Table 4 Models predicting daily negative affect (high and low activation; HA, LA)

\begin{tabular}{|c|c|c|c|c|c|c|c|}
\hline Model & $\begin{array}{l}\text { Coefficient } \\
\text { (log odds) }\end{array}$ & SE & $\begin{array}{l}\text { Odds } \\
\text { ratio }\end{array}$ & Model & $\begin{array}{l}\text { Coefficient } \\
\text { (log odds) }\end{array}$ & SE & $\begin{array}{l}\text { Odds } \\
\text { ratio }\end{array}$ \\
\hline \multicolumn{8}{|c|}{ High activation negative affect } \\
\hline $\begin{array}{l}\text { 5. PA (vs. no-PA) with } \\
\text { high activation affect }\end{array}$ & & & & $\begin{array}{l}\text { 6. PA (vs no-PA) and passion } \\
\text { with high activation affect }\end{array}$ & & & \\
\hline Fixed effects & & & & Fixed effects & & & \\
\hline Intercept, $\beta_{00}$ & $-0.64^{* *}$ & 0.23 & 0.53 & Intercept, $\beta_{00}$ & $-0.64^{* *}$ & 0.23 & 0.53 \\
\hline $\mathrm{PA}, \beta_{10}$ & $1.31^{* * *}$ & 0.24 & 3.71 & Harmonious passion, $\beta_{01}$ & -0.34 & 0.18 & 0.71 \\
\hline Random effects ${ }^{a}$ & & & & Obsessive passion ${ }^{\mathrm{b}}, \beta_{02}$ & -0.10 & 1.06 & 0.91 \\
\hline Intercept, $\sigma_{u o}^{2}$ & $2.51^{* * *}$ & 1.58 & & PA day, $\beta_{10}$ & $1.31^{* * *}$ & 0.24 & 3.71 \\
\hline \multirow[t]{3}{*}{ Residual variance, $e$} & 0.81 & 0.90 & & Random effects $^{\mathrm{a}}$ & & & \\
\hline & & & & Intercept, $\sigma_{u 0}^{2}$ & $2.41^{* * *}$ & 1.55 & \\
\hline & & & & Residual variance, $e$ & 0.81 & 0.90 & \\
\hline \multicolumn{8}{|c|}{ Low activation negative affect } \\
\hline $\begin{array}{l}\text { 7. PA (vs. no-PA) with } \\
\text { low activation affect }\end{array}$ & & & & $\begin{array}{l}\text { 8. PA (vs no-PA) and passion } \\
\text { with low activation affect }\end{array}$ & & & \\
\hline Fixed effects & & & & Fixed effects & & & \\
\hline Intercept, $\beta_{00}$ & -0.36 & 0.30 & 0.70 & Intercept, $\beta_{00}$ & -0.37 & 0.30 & 0.53 \\
\hline $\mathrm{PA}, \beta_{10}$ & $0.77^{* *}$ & 0.26 & 2.17 & Harmonious passion, $\beta_{01}$ & -0.403 & 0.35 & 0.77 \\
\hline Random effects ${ }^{a}$ & & & & Obsessive passion, $\beta_{02}$ & 1.43 & 1.28 & 1.03 \\
\hline Intercept, $o_{u o}^{2}$ & $4.70^{* * *}$ & 2.17 & & $\mathrm{PA}, \beta_{10}$ & 0.76 & 0.25 & 3.60 \\
\hline $\mathrm{PA}, \sigma_{u 1}^{2}$ & $1.53^{* *}$ & 1.24 & & Harmonious passion, $\beta_{11}$ & -0.10 & 0.22 & 0.68 \\
\hline \multirow[t]{5}{*}{ Residual variance, $e$} & 0.73 & 0.85 & & Obsessive passion ${ }^{\mathrm{b}}, \beta_{12}$ & -1.85 & 1.09 & 0.66 \\
\hline & & & & Random effects ${ }^{a}$ & & & \\
\hline & & & & Intercept, $\sigma_{u 0}^{2}$ & $4.62^{* * *}$ & 2.15 & \\
\hline & & & & $\mathrm{PA}, \sigma_{u 1}^{2}$ & $1.27^{+}$ & 1.13 & \\
\hline & & & & Residual variance, $e$ & 0.73 & 0.85 & \\
\hline
\end{tabular}

Note. Unstandardized Estimates; SE = Standard Error; PA = Physical Activity.

a Variance component estimates and standard deviations are provided for Random Effects.

${ }^{\mathrm{b}}$ Log transformed Obsessive passion variable.

${ }^{\dagger} \mathrm{p}=.10 .{ }^{*} \mathrm{p}<.05 .{ }^{* *} \mathrm{p}<.01 .{ }^{* * *} \mathrm{p}<.001$.

variables with respect to the slope of activity engagement (vs. not engaging) and positive affect.

To underscore these latter associations for purpose three, a simpler model of slope variability only was tested, with passion types as random level-2 predictors of the level-1 activity engagement slope (Model 2-B Table 1). Results showed that HP levels moderated the relation between activity engagement and high activation positive affect, $t(57)=2.89$, $p<.01$. Moreover, OP levels also moderated this relationship but in the opposite direction, $t(57)=-2.23, p<.05$. Partitioning participants into passion groups helped to interpret these interactions. From Figure 1, the more harmoniously passionate women experienced greater high activation positive affect overall and this remained fairly stable across days when they did and did not engage in physical activity. Conversely, obsessively passionate women showed a noticeable drop in positive affect when they did not engage in physical activity $(M=22.74)$ compared to days when they did engage $(M=28.98)$. 


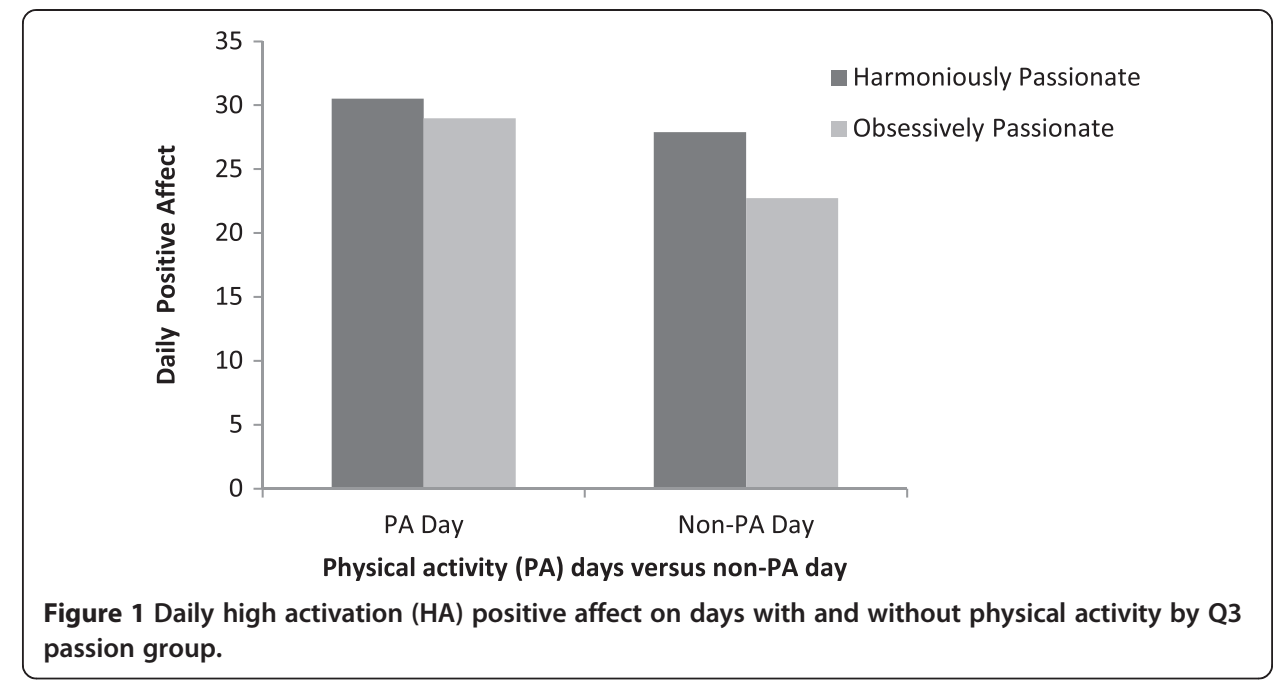

A model with analyses of slopes and means as outcome was also tested for low activation positive affect. The conditional model with passion variables was not a superior fit to the simpler model with activity engagement only, $X^{2}(4)=5.93$, $p=.20$. On days when participants were active, neither passion types were significantly associated with low activation positive affect (Model 4 in Table 3), albeit the associations were in the expected directions [HP: $t(57)=1.38, p=0.17$; OP: $t(57)=-1.24, p=.22$ ]. In regards to purpose three, neither type of passion moderated the relationship between activity engagement and daily low activation positive affect $(p s>.05)$.

\section{Negative affect}

Next, a Bernoulli regression model of means as outcomes was tested in order to examine the direct influence of HP and OP on high activation negative affect. Given that there was no significant variability between participants in the association for activity engagement, it was not statistically warranted to add level-2 predictors of a fixed slope. Echoing results for positive affect, neither HP levels, $t(57)=-1.88, p=.07$, nor OP levels, $t(57)=-0.90, p=.929$ were significantly related to greater scores on negative high activation affect. The marginally significant effect of HP can be interpreted such that each increase of one point in HP resulted in 33\% lower odds of scoring high on negative affect, factoring in the effect of engaging in physical activity. All odds ratios and coefficients can be found in Table 4. Despite non-significant random variability in a level 1 parameter (e.g., slope), level 2 predictors may be added to a model and interpreted with caution provided there be theoretical justification for their inclusion (Luke, 2004). Still, a Bernoulli model with analyses of means and slopes showed that neither type of passion moderated the relationship between engaging in physical activity and high activation negative affect ( $p$ s $>.05$; not shown in Table 4 ).

Analyses of Bernoulli models (random slope) were repeated for daily low activation negative affect. Similar to the above findings, there were no direct or 
moderating effects of HP or OP on the probability of scoring higher on low activation negative affect.

\section{Purpose 4: passion and vitality}

Finally, the relationship between passion (baseline) and levels of vitality measured at endpoint, that is, after the 14-day experience sampling component was examined. First, and after covarying out the effect of physical activity levels, results showed that women in the harmoniously passionate group scored higher on endpoint vitality than women in the obsessively passionate group, $F(1,57)=13.57$, $p<.01, \eta^{2}=.19$. Next, hierarchical regression analyses with all participants (nongrouped) helped dissect the relative, prospective influence of each type of passion. Preliminary bivariate correlations showed that older and more active participants had significantly greater vitality $(r \mathrm{~s}=.28, \mathrm{p}<.05)$. After controlling for both variables in step 1 of the regression (i.e., age, LTEQ), passion variables explained a significant portion of variance in endpoint vitality, $F(4,59)=5.24 p<.01, R^{2}=.28$, $R^{2}$ change $=.15$. Specifically, HP was positively related to vitality $(\beta=.33, p<.01)$ while OP was negatively related $(\beta=-.28, p<.05)$.

\section{Discussion}

The global objective of this experience sampling study with active, working mothers was to examine the influence of passion towards physical activity on daily positive and negative affect as well as more generally in terms of vitality. Overall, the results lend support for the tenets of the DMP and they generate new paths of enquiry. This study has several strong points. Firstly, the focus of this study was on passion for physical activity which has seldom been studied independently as a passion despite the fact it lends itself remarkably well to the DMP and that it has important ties to mental health (Parastatidou et al. 2012; Melville 2012). Secondly, this research was conducted with active, multiple-role women. They represent a unique population given the juggling that is required to incorporate a passion for physical activity into their busy daily lives. Moreover, women tend to have lower mental health than men and this must be better addressed (Hopkins Fishel 2008). Thirdly, four components of affect across valence (positive, negative) and activation (high, low) dimensions were evaluated which provided a more representative indicator of day-to-day well-being. Lastly, we capitalized on the experience sampling method, whereby we collected longitudinal, naturalistic self-report data in real-time.

All but three of the women that participated in this study were passionate toward physical activity, which they reported engaging in on close to 10 days (out of 14). On these activity days, the women reported higher overall levels of positive affect as well as lower negative affect compared to days when they did not engage, and this supported our hypotheses for purpose one. This is in-line with the DMP and similar conclusions in the domains of sport (Vallerand et al. 2008) and work (Vallerand and Houlfort, 2003) among others, as well as investigations that attest to the cross-domain applicability of the model (Vallerand et al. 2003; Mageau and Vallerand 2007). We conclude that engaging in physical activity as one's passionate activity appears to be associated with and/or contribute to regular affective benefits. 
This finding may relate to certain qualities inherent to this health behaviour. Carbonneau et al. (2010) followed the same line of reasoning to study the emotional outcomes of a passion for yoga, citing well-documented mind-body benefits that accompany a regular yoga practice. Our study expands on theirs by examining a breadth of physical activities and by gathering repeated assessments of daily affect rather than one-time retrospective reports of positive and negative emotions experienced during the activity (i.e., during yoga). Because of this, it was deemed relevant to assess both high and low activation affective states as both are likely to transpire over the course of a day. Incidentally, and unique to this study, it was observed that engaging in one's passion for physical activity explained a similar proportion of variance in both high and low activation positive affect. Therefore it is likely that the rush and excitement of engaging in one's passion can be accompanied by feelings of calmness and serenity over a day's course. Other researchers have also reported that women experience fluctuations in both high and low activation states throughout the day, such as feelings of tranquility and exhaustion, and that these are sensitive to physical activity engagement (e.g., Focht et al. 2004). It may be worthwhile in future investigations to examine and/or control for biases pertaining to the time of day the physical activity occurred and relating to retrospective recall over a day's course.

In the objectives that followed, we queried the dual conceptualization of passion within the (Vallerand et al. 2003) model for a more thorough understanding of the above effects. Individual hypotheses for our second purpose, regarding the respective influences of HP and OP on women's daily affect, and on physical activity days specifically, were not supported statistically. Firstly, the autonomous internalization that typifies a HP was not significantly more beneficial emotionally over a day's course than having engaged in the passionate activity itself, though this association was positive. Albeit this study was novel in analyzing an overall rating of daily affect, ours is not the first to have found non-significance for HP in relation to positive emotions (Ratelle et al., 2004), nor with respect to negative affectivity (Mageau et al. 2005). Still, the findings are not fully in line with the DMP nor with (Mageau and Vallerand 2007) who found that HP had a positive impact on positive affect assessed at the end of the day.

Secondly, higher levels of OP, stemming from a rigid and uncontrollable urge to engage in physical activity, did not appear to be emotionally injurious on days when the women engaged in the activity. As per (Ratelle et al. 2004), our relationship between $\mathrm{OP}$ and daily positive daily affect was negative, though it was non-significant and this is consistent with Mageau and Vallerand (2007). Still, true to the DMP, engaging in physical activity out of an OP should be associated with poorer emotional states given one's rigid and defensive orientation. A few factors could account for why our findings disagree with others that support this theoretical association. First, links have largely been documented during or shortly after activity engagement (Stenseng et al. 2011; Mageau et al. 2005), whereas in this study an overall daily rating of negative affect was unrelated to OP on days when the women engaged in their passion. Second, borrowing from recent motivational theory-based studies (e.g., Guérin and Fortier 2012) it stands to reason that more agreeable affect for women with higher OP could be tied to a catharsis type of effect on days when they engage in physical activity. Namely, they may experience relief from feelings of guilt and anxiety attached to the activity and/or, in this population specifically, possibly also a feeling of gratification from having "fit it in". 
Future qualitative work would be ideally suited to expose such possible origins of these results. Such investigations may be a good opportunity to examine the role of additional psychological characteristics such as neuroticism and/or mood disorders, which have been linked to excessive levels of guilt and may carry implications in terms of developing an obsessive passion (Beck \& Alford, 2009). However, further restricting inclusion criteria among participants in order to highlight such qualities would limit the generalizability of unique results to other groups of individuals, which was already a limitation of using highly selective sample in the present study.

It is also important to acknowledge the likelihood of measurement issues in explaining the absence of certain associations. For instance, potential ceiling effects for positive affect may have reduced the variance left to be explained by passion variables. In addition, participants consistently reported minimal scores for high and low activation negative affect (i.e., floor effects). Although dichotomizing the variables permitted analysing the data, raw score specificity was lost. Moreover, the possibility of biased responding cannot be ignored as a limitation, in that the women in this sample may have avoided full disclosure of their negative affect (Fujita et al. 1991). Whether such social desirability effects are unique to our population of women or not, they may need to be controlled for in future studies.

With some caution, results of this study so far support that women who are passionate about physical activity can reap its well-established emotional benefits and that the orientation of this passion, be it more harmonious and/or obsessive, tends to have a neutral effect on daily affective states, at least on days when women are active. But as per the DMP, the act of engaging in the passionate activity presents only one side of the passion equation with respect to well-being. Indeed, the third purpose of this study was to examine the moderating effect of passion types on the relationship between participating in physical activity (versus not) and daily affect.

Consistent with Mageau and Vallerand (2007) and our hypothesis, we found that OP exerted a significant moderating influence on positive affect (high activation), such that greater OP levels resulted in lower positive affect on days when participants were not active. This lends added support for the DMP, namely that OP is tied to a dependence on the passionate activity, which leads to substantial frustration when one cannot partake in it (Vallerand 2010). The moderating influence of HP was a unique finding of this study since (Mageau and Vallerand 2007) did not see a significant effect. Groupbased values can be interpreted such that being more harmoniously passionate fosters more stable positive affectivity that is less conditional on engaging in the passionate activity. According to (Vallerand 2010) this reflects an ability to adapt and focus energy elsewhere, which would be highly advantageous for women juggling many roles and responsibilities. Contrary to our hypotheses and tenets of the model, there were no moderating effects of HP nor OP for negative affect. Aforementioned measurement issues at a surface level may have played a role. On more theoretical grounds however, claims within the DMP pertain to being prevented from engaging in the activity. As a weakness of the current study, we did not inquire as to whether participants freely chose not to engage in physical activity or whether internal (i.e., injury) or external (e.g., daycare cancelation) circumstances prevented them from doing so. Such nuances in activity non-engagement may be particularly relevant in this population, and should be assessed in forthcoming investigations. 
Being prevented from engaging in physical activity could lead obsessively passionate women to ruminate about the activity when not engaging in it (Donahue et al. 2012; Vallerand 2008). Maladaptive ruminations are one of the mechanisms that have been suggested to explain the influence of passion types on well-being. Other mechanistic influences that have received support include flow as well as enjoyment when engaged in the activity (Carpentier et al. 2012; Parastatidou et al. 2012). Specifically, individuals with greater HP tend to experience higher amounts of flow while partaking not only in the passionate activity but in other endeavours as well, and this can improve well-being. In future studies, dissecting the cognitions and feelings that also arise when partaking in competing, non-passionate activities and linking them to daily affective states would be informative, particularly among people who identify with the pursuit of many roles and responsibilities. These propositions tie in well with a more general assumption in this literature, namely that passion facilitates greater overall well-being through an accumulation of positive emotional experiences (Vallerand et al. 2007). Thus, it seems relevant to also examine enduring indicators of well-being (i.e., vitality) that can accrue over time in order to understand the progressive influence of one's internalization of the passionate activity.

Thus, in a final purpose we examined passion types in association with levels of vitality assessed at the end of the 14-day study. Assessing vitality can also complement evaluations of more hedonic indicators of well-being like affect to provide a broader conceptualization of well-being (Ryan and Deci, 2001). As expected and after controlling for age and physical activity levels, we found that vitality was negatively predicted by OP but positively by HP. This is in accordance with the DMP as well as previous research (e.g., Philippe et al., 2009). We found this to be true not only for absolute levels of each type of passion but also when the women were divided based on their most salient passion type. Others have confirmed similar relationships cross-sectionally, as well as with vitality (and also life satisfaction) assessments after three and 12 months (Rousseau and Vallerand 2008; Philippe et al. 2009; Vallerand et al. 2007). Our results imply that researchers need to be cautious in generalizing the findings regarding vitality from the physical activity literature to all women-clearly, women's internalization processes of physical activity need to be considered to promote a healthy participation. More specifically, our results suggest that while harmoniously passionate women are more likely to reap long-term, eudemonic and energizing benefits from physical activity, higher OP can result in degradation on the vitality spectrum toward exhaustion. In our study, daily low activation negative affect ${ }^{2}$ was unrelated to passion types which also suggests that the effect might only transpire gradually.

The findings from this study carry practical implications for well-being which complement our theoretical deliberations. Although eradicating a passionate activity altogether is one possible solution when an OP leads to deleterious effects (Vallerand 2010), this seems more applicable to acts such as gambling than physical activity, which is an essential component of a healthy lifestyle. Our results highlight the need to intervene with respect to women's internalization of physical activity into their sense of self, which would mean progressing towards a more harmonious passion and away from an obsessive passion. An autonomous orientation may be sufficient for active, busy women to stay balanced while reaping the emotional benefits of this type of activity (Forest et al. 2012). Either way, several specific tactics may be useful: a) attending to the reasons why 
one began partaking in the activity while focusing on enjoyment b) group-based exercise sessions without any contingencies attached to activity; c) self-regulation strategies focused on investing energy in alternative activities and setting moderate physical activity goals, thus reducing anxiety. Testing the relevance and efficacy of these applications should be considered in future intervention research. Moreover, forthcoming studies should seek to further explore interesting underlying mechanisms as previously suggested while also addressing the limitations that have been acknowledged throughout this discussion.

\section{Conclusions}

This study offers added support for the applicability and theoretical relevance of the DMP in the physical activity context and among physically active working mothers. Results showed that engaging in physical activity for which one is passionate leads to benefits in daily affect. However, being more obsessively passionate was associated with worse affect on non-physical activity days and with lower vitality over a two-week period. Harmonious passion lead to more stable positive affect and greater vitality over time.

\section{Endnotes}

${ }^{1}$ Physical activity is defined as movement of the body that results in energy expenditure; this can be freely chosen and/or integrated into one's routine. Exercise is similarly defined but is more restrictive in that it refers to movement that is planned, structured and repetitive with an objective of maintaining/improving fitness (Biddle and Mutrie 2008). For the purposes of this paper we will employ the more global term of physical activity in order to capture a broader spectrum of activities. That said, we continue to use the term exercise when it applies to the cited literature

${ }^{2}$ Items added to the PANAS to assess low activation affect: relaxed, at rest, serene, calm, at ease (positive); tired, sluggish, droopy, dull, bored, drowsy (negative; Barrett and Russell 1998)

${ }^{3}$ The 60 passionate women were not significantly different from the full sample $(\mathrm{N}=63)$ with respect to basic demographic and physical activity variables [Age $=42.75$ years $(S D=5.56), \mathrm{BMI}=22.46(S D=2.54), \mathrm{LTEQ}=52.65(S D=18.55$, range: 9-102]

${ }^{4}$ Given the results of previous studies (e.g., Guerin and Fortier accepted) models of affect were all tested for the influence of RPE (square root transformed). The fixed effect of RPE on daily high activation positive affect was significant, $t(713)=3.53$, $\mathrm{p}<.001$. Testing of high activation models appearing in subsequent sections was repeated controlling for the each participant's average RPE value at level 2. There were no significant changes in model fit with the inclusion of average RPE and the coefficient remained largely unaffected. Not surprisingly, RPE was not related to low activation positive affect $(p=.84)$. Therefore, no analyses with RPE are presented in this paper

${ }^{5}$ All mentions of OP refer to the log transformed variable. 


\section{Competing interests}

The authors declare that they have no competing interests.

\section{Authors' contributions}

EG and MF were involved in the conceptualization and planning of the study. EG oversaw the study protocol and EG and TW coordinated the data collection. MF supervised all facets of the project. EG and TW assumed responsibility for the cleaning and organization of the data while EG took charge of analyses and statistical interpretation of the data. EG wrote the manuscript with significant input and revisions from MF and TW. All authors approved the final manuscript.

\section{Acknowledgements}

The authors extend their gratitude to Stephanie Corras and Michelle Prentice for their research assistance in this larger project as well as Dr. Shane Sweet for statistical consultation throughout the analysis stage. In addition, assistance from Jason McCormick (Twilight City Software, Inc.) in the development of the software application was invaluable to this project. The authors also wish to acknowledge the input and contributions from Dr. Shaelyn Strachan to the larger project. The first author received funding from SSHRC and OGS.

\section{Author details}

${ }^{1}$ School of Human Kinetics, University of Ottawa, 125 University Pr, K1N 6N5, Ottawa, ON, Canada. ${ }^{2}$ School of Human Kinetics, University of Ottawa, Ottawa, Canada.

Received: 2 January 2013 Accepted: 28 September 2013

\section{Published: 11 Nov 2013}

\section{References}

Abercrombie, HC, Kalin, NH, \& Davidson, RJ (2005). Acute cortisol elevations cause heightened arousal ratings of objectively nonarousing stimuli. Emotion, 5, 354-359.

Barrett, LF, \& Russell, JA (1998). Independence and bipolarity in the structure of current affect. Journal of Personality and Social Psychology, 74, 967-984.

Beck, AT, \& Alford, BA (2009). Depression: causes and treatment (2nd ed.). Philadelphia: University of Pennsylvania Press.

Berger, BG, \& Motl, RW (2000). Exercise and mood: a selective review and synthesis of research employing the profile of mood states. Journal of Applied Sport Psychology, 12, 69-92.

Biddle, J, \& Ekkekakis, P (2005). Physically active lifestyles and well-being. In FA Huppert, N Baylis, \& B Keverne (Eds.), The science of well-being (pp. 140-168). Oxford, NY: Oxford University Press.

Biddle, SJH, \& Mutrie, N (2008). Psychology of physical activity and exercise: determinants, well-being and interventions (2nd ed.). New York: Routledge.

Borg, GAV (1982). Psychophysical bases of perceived exertion. Medicine and Science in Sports and Exercise, 14, 377.

Brown, W, Mishra, G, Lee, C, \& Bauman, A (2000). Leisure time physical activity in australian women: relationship with well being and symptoms. Research Quarterly for Exercise and Sport, 71, 206-216.

Carbonneau, N, Vallerand, RJ, \& Massicotte, S (2010). Is the practice of yoga associated with positive outcomes? The role of passion. The Journal of Positive Psychology, 5, 452-465.

Carpentier, J, Mageau, GA, \& Vallerand, RJ (2012). Ruminations and flow: why do people with a more harmonious passion experience higher well-being? Journal of Happiness Studies, 13, 501-518.

Cramp, AG, \& Bray, SR (2010). Postnatal Women's feeling state responses to exercise with and without baby. Maternal and Child Health Journal, 14, 343-349.

Csikszentmihalyi, M, \& Larson, R (1987). Validity and reliability of the experience-sampling method. The Journal of Nervous and Mental Disease, 175, 526-535.

Denton, M, Prus, S, \& Walters, V (2004). Gender differences in health: a Canadian study of the psychosocial, structural and behavioural determinants of health. Social Science \& Medicine, 58, 2585-2600.

Donahue, EG, Forest, J, Vallerand, RJ, Lemyre, PN, Crevier-Braud, L, \& Bergeron, É (2012). Passion for work and emotional exhaustion: the mediating role of rumination and recovery. Applied Psychology: Health and WellBeing, 4, 341-368.

Donahue, EG, Rip, B, \& Vallerand, RJ (2009). When winning is everything: on passion, identity, and aggression in sport. Psychology of Sport and Exercise, 10, 526-534.

Duncan, LR, Hall, CR, Wilson, PM, \& O, J (2010). Exercise motivation: a cross-sectional analysis examining its relationships with frequency, intensity, and duration of exercise. International Journal of Behavioral Nutrition and Physical Activity, $7(1), 1-7$.

Ekkekakis, P, \& Petruzzello, SJ (2001). Analysis of the affect measurement conundrum in exercise psychology: Il: a conceptual and methodological critique of the exercise-induced feeling inventory. Psychology of Sport and Exercise, $2,1-26$.

Elavsky, S, \& McAuley, E (2005). Physical activity, symptoms, esteem, and life satisfaction during menopause. Maturitas, $52,374-385$.

Focht, BC, Gauvin, L, \& Rejeski, WJ (2004). The contribution of daily experiences and acute exercise to fluctuations in daily feeling states among older, obese adults with knee osteoarthritis. Journal of Behavioral Medicine, 27, 101-121.

Forest, J, Mageau, GA, Crevier-Braud, L, Bergeron, É, Dubreuil, P, \& Lavigne, GL (2012). Harmonious passion as an explanation of the relation between signature strengths' use and well-being at work: test of an intervention program. Human Relations, 65, 1233-1252.

Fujita, F, Diener, E, \& Sandvik, E (1991). Gender differences in negative affect and well-being: the case for emotional intensity. Journal of Personality \& Social Psychology, 61, 427-434. 
Galper, DI, Trivedi, MH, Barlow, CE, Dunn, AL, \& Kampert, JB (2006). Inverse association between physical inactivity and mental health in men and women. Medicine and Science in Sports and Exercise, 38, 173-178.

Gauvin, L, Rejeski, WJ, \& Reboussin, BA (2000). Contributions of acute bouts of vigorous physical activity to explaining diurnal variations in feeling states in active, middle-aged women. Health Psychology, 19, 365-375.

Giacobbi, PR, Hausenblas, HA, \& Frye, N (2005). A naturalistic assessment of the relationship between personality, daily life events, leisure-time exercise, and mood. Psychol Sport Exercise, 6, 67-81.

Godin, G (2011). The godin-shephard leisure-time physical activity questionnaire. The Health \& Fitness Journal of Canada, $4,18-22$.

Godin, G, \& Shephard, RJ (1985). A simple method to assess exercise behavior in the community. Canadian Journal of Applied Sport Sciences, 10, 141-146.

Guérin, E, \& Fortier, MS (2012). Situational motivation and perceived intensity: their interaction in predicting changes in positive affect from physical activity. Journal of Obesity, 2012(269320), 1-7.

Guérin, Fortier, \& Williams. (Unpublished). Physical activity, non-physically active leisure and well-being in active women with multiple roles.

Hair, JF, Anderson, RE, Tatham, RL, \& William, C (1998). Multivariate data analysis (5th ed.). Upper Saddle River, NJ: Prentice Hall.

Hamer, M, Karageorghis, C, \& Vlachopoulos, S (2002). Motives for exercise participation as predictors of exercise dependence among endurance athletes. The Journal of Sports Medicine and Physical Fitness, 42, $233-238$.

Hausenblas, HA, \& Downs, S (2002). Exercise dependence: a systematic review. Psychology of Sport and Exercise, 3, 89-123.

Hektner, J, Schmidt, J, \& Csikszentmihályi, M (2007). Experience sampling method: measuring the quality of everyday life. Thousand Oaks, CA: Sage.

Hopkins Fishel, A (2008). Prevalence of mental illness. In C Ingram Fogel \& N Fugate Woods (Eds.), Women's health care in advanced practice nursing (pp. 253-294)). New York: Springer.

Hox, JJ (2010). Multilevel analysis: techniques and applications (2nd ed.). New York: Routledge.

Hyde, AL, Conroy, DE, Pincus, AL, \& Ram, N (2011). Unpacking the feel-good effect of free-time physical activity: between- and within-person associations with pleasant-activated feeling states. Journal of Sport \& Exercise Psychology, 33, 884-902.

Jacobs, DR, Ainsworth, BE, Hartman, TJ, \& Leon, AS (1993). A simultaneous evaluation of 10 commonly used physical activity questionnaires. Medicine and Science in Sports and Exercise, 25, 81-91.

Kelsey, KS, DeVellis, BME, Begum, M, Belton, L, Hooten, EG, \& Campbell, MK (2006). Positive affect, exercise and selfreported health in blue-collar women. American Journal of Health Behavior, 30, 199-207.

Kreft, IGG, \& De Leeuw, J (1998). Introducing multilevel modeling. Thousand Oaks, CA: Sage.

Kull, M (2002). The relationships between physical activity, health status and psychological well-being of fertility-aged women. Scandinavian Journal of Medicine \& Science in Sports, 12, 241-247.

Kwan, BM, \& Bryan, AD (2010). Affective response to exercise as a component of exercise motivation: attitudes, norms, self-efficacy, and temporal stability of intentions. Psychology of Sport and Exercise, 11, 71-79.

Lasswell, M (2002). Marriage and family. In S Kornstein \& A Clayton (Eds.), Women's mental health (pp. 515-526). New York: Guildford Press.

Luke, DA (2004). Multilevel modeling (3rd ed.). Thousand Oaks, CA: Sage.

Mageau, GA, Vallerand, RJ, Charest, J, Salvy, SJ, Lacaille, N, Bouffard, T, et al. (2009). On the development of harmonious and obsessive passion: the role of autonomy support, activity specialization, and identification with the activity. Journal of Personality, 77, 601-646.

Mageau, GA, Vallerand, RJ, Rousseau, FL, Ratelle, CF, \& Provencher, PJ (2005). Passion and gambling: investigating the divergent affective and cognitive consequences of gambling. Journal of Applied Social Psychology, 35, 100-118.

Mageau, GA, \& Vallerand, RJ (2007). The moderating effect of passion on the relation between activity engagement and positive affect. Motivation and Emotion, 31, 312-321.

McCoach, DB, \& Black, AC (2008). Evaluation of model fit and adequacy. In AA O'Connell \& DB McCoach (Eds.), Multilevel modeling of educational data (pp. 245-272). Greenwich: Information Age Publishing.

Melville, N (2012). Exercise gains momentum as psychiatric treatment: resource document. Medscape news. http://www. medscape.com/viewarticle/774639. Accessed 3 december 2012.

Nezlek, JB (2008). An introduction to multilevel modeling for social and personality psychology. Social and Personality Psychology Compass, 2, 842-860.

Nix, GA, Ryan, RM, Manly, JB, \& Deci, EL (1999). Revitalization through self-regulation: the effects of autonomous and controlled motivation on happiness and vitality. Journal of Experimental Social Psychology, 35, 266-284.

Noble, RE (2005). Depression in women. Metabolism, 54, 49-52.

Parastatidou, IS, Doganis, G, Theodorakis, Y, \& Vlachopoulos, SP (2012). Exercising with passion: initial validation of the passion scale in exercise. Measurement in Physical Education and Exercise Science, 16, 119-134.

Pearson, QM (2008). Role overload, job satisfaction, leisure satisfaction, and psychological health among employed women. Journal of Counseling \& Development, 86, 57-63.

Penedo, FJ, \& Dahn, JR (2005). Exercise and well-being: a review of mental and physical health benefits associated with physical activity. Current Opinion in Psychiatry, 18, 189-193.

Philippe, FL, Vallerand, RJ, \& Lavigne, GL (2009). Passion does make a difference in people's lives: a look at well-being in passionate and non-passionate individuals. Applied Psychology: Health and Well-Being, 1, 3-22.

Ratnasingham, S, Cairney, J, Rehm, J, Manson, H, \& Kurdyak, PA (2012). Opening eyes, opening minds: the Ontario burden of mental illness and addictions report: resource document. Public Health Ontario. http://www.ices.on.ca/webpage. cfm?site_id=1\&org_id=31\&morg_id=0\&gsec_id=0\&item_id=7718, Accessed October 6th, 2013.

Ratelle, CF, Vallerand, RJ, Mageau, GA, Rousseau, FL, \& Provencher, P (2004). When passion leads to problematic outcomes: a look at gambling. Journal of Gambling Studies, 20, 105-119.

Raudenbush, S, Bryk, A, Cheong, YF, Congdon, R, \& Du Toit, M (2004). HLM 6: hierarchical linear and nonlinear modeling. Lincolnwood, IL: Scientific Software International. 
Raudenbush, SW, \& Bryk, AS (2002). Hierarchical linear models: applications and data analysis methods. Thousand Oaks, CA: Sage.

Reed, J, \& Buck, S (2009). The effect of regular aerobic exercise on positive-activated affect: a meta-analysis. Psychology of Sport and Exercise, 10, 581-594.

Rousseau, FL, \& Vallerand, RJ (2008). An examination of the relationship between passion and subjective well-being in older adults. International Journal of Aging \& Human Development, 66, 195-211.

Russell, JA (1980). A circumplex model of affect. Journal of Personality and Social Psychology, 39, 1161-1178.

Russell, JA (2003). Core affect and the psychological construction of emotion. Psychological Review, 110, 145-172.

Russell, WD, \& Newton, M (2008). Short-term psychological effects of interactive video game technology exercise on mood and attention. Educational Technology \& Society, 11, 294-308.

Ryan, RM, \& Deci, EL (2001). On happiness and human potentials: a review of research on hedonic and eudaimonic well-being. Annual Review of Psychology, 52, 141-166.

Ryan, RM, \& Frederick, C (1997). On energy, personality, and health: subjective vitality as a dynamic reflection of well-being. Journal of Personality, 65, 529-565.

Scollon, NC, Prieto, CK, \& Diener, E (2003). Experience sampling: promises and pitfalls, strength and weaknesses. Journal of Happiness Studies, 4, 5-34.

Stenseng, F, Rise, J, \& Kraft, P (2011). The dark side of leisure: obsessive passion and its covariates and outcomes. Leisure Studies, 30, 49-62.

Tabachnick, BG, \& Fidell, LS (2007). Using multivariate statistics. Boston: Allyn \& Bacon.

Tremblay, MS, Kho, ME, Tricco, AC, \& Duggan, M (2010). Process description and evaluation of Canadian physical activity guidelines development. International Journal of Behavioral Nutrition and Physical Activity, 7(1), 42.

Vallerand, RJ (2008). On the psychology of passion: in search of what makes people's lives most worth living. Canadian Psychologist, 49, 1-13.

Vallerand, RJ (2012). The role of passion in sustainable psychological well-being. Psychology of Well-being: Theory, Research, and Practice, 2(1), 1-21.

Vallerand, RJ, Blanchard, CM, Mageau, GA, Koestner, R, Ratelle, C, Leonard, M, et al. (2003). Les passions de l'Ame: on obsessive and harmonious passion. Journal of Personality and Social Psychology, 85, 756-767.

Vallerand, RJ, \& Houlfort, N (2003). Passion at work: toward a new conceptualization. In D Skarlicki, S Gilliland, \& D Steiner (Eds.), Research in social issues in management (Vol. 3, pp. 175-204). Greenwich, CT: Information Age Publishing Inc.

Vallerand, RJ, Mageau, GA, Elliot, AJ, Dumais, A, Demers, M, \& Rousseau, FL (2008). Passion and performance attainment in sport. Psychology of Sport and Exercise, 9, 373-392.

Vallerand, RJ, Salvy, S, Mageau, GA, Elliot, AJ, Denis, PL, Grouzet, FM, et al. (2007). On the role of passion in performance. Journal of Personality, 75, 505-534.

Vallerand, RJ (2010). On passion for life activities: the dualistic model of passion. In MP Zanna (Ed.), Advances in experimental social psychology (Vol. 42, pp. 97-193). New York: Academic Press.

Vancour, M (2009). Motherhood, balance, and health behaviours of academic women. Journal of the Motherhood Initiative for Research and Community Involvement, 11, 151-166.

Verner-Filion, J, Lafrenière, MAK, \& Vallerand, RJ (2012). On the accuracy of affective forecasting: the moderating role of passion. Personality and Individual Differences, 52, 849-854.

Vuillemin, A, Boini, S, Bertrais, S, Tessier, S, Oppert, JM, Hercberg, S, et al. (2005). Leisure time physical activity and health-related quality of life. Preventive Medicine, 41, 562-569.

Ware, JE, Jr (2000). SF-36 health survey update. Spine, 25, 3130-3139.

Ware, JE, Jr, \& Sherbourne, C D (1992). The MOS 36-item short-form health survey (SF-36): I: conceptual framework and item selection. Medical Care, 30, 473-483.

Watson, D, Clark, LA, \& Tellegen, A (1988). Development and validation of brief measures of positive and negative affect: the PANAS scales. Journal of Personality and Social Psychology, 54, 1063-1070.

Wendel-Vos, G, Schuit, A, Tijhuis, M, \& Kromhout, D (2004). Leisure time physical activity and health-related quality of life: cross-sectional and longitudinal associations. Quality of Life Research, 13, 667-677.

Wichers, M, Peeters, F, Rutten, BPF, Jacobs, N, Derom, C, Thiery, E, et al. (2012). A time-lagged momentary assessment study on daily life physical activity and affect. Health Psychology, 31, 135-144.

10.1186/2211-1522-3-4

Cite this article as: Guérin et al:: "I just NEED to move...": examining women's passion for physical activity and its

relationship with daily affect and vitality. Psychology of Well-Being: Theory, Research and Practice 2013, 3:4

Submit your manuscript to a SpringerOpen ${ }^{\circ}$ journal and benefit from:

- Convenient online submission

- Rigorous peer review

- Immediate publication on acceptance

- Open access: articles freely available online

- High visibility within the field

Retaining the copyright to your article

Submit your next manuscript at $\boldsymbol{\wedge}$ springeropen.com 